\title{
Clinical features of drusenoid pigment epithelial detachment in age related macular degeneration
}

\author{
W Roquet, F Roudot-Thoraval, G Coscas, G Soubrane
}

Br J Ophthalmol 2004;88:638-642. doi: 10.1136/bjo.2003.017632

\begin{abstract}
Aim: To analyse clinical features of drusenoid pigment epithelium detachment (PED) in age related macular degeneration.

Methods: 61 eyes of 32 patients with untreated drusenoid PED were followed for an average of 4.6 years (range 1-17 years). Drusenoid PED was defined as $1 / 2$ disc diameter (DD) of confluent soft drusen under the centre of the macula. All patients underwent visual acuity measurement, biomicroscopic fundus examination, stereoscopic colour photograph, and fluorescein and indocyanine green angiography. Optical coherence tomography was performed in selected cases at the last examination. Kaplan Meier survival analysis was performed to estimate the probability of complications. Results: Three different natural outcomes were identified: persistence of drusenoid PED (38\%), development of geographic atrophy (49\%), and choroidal neovascularisation (CNV) (13\%). Based on Kaplan Meier survival analysis, drusenoid PED had a $50 \%$ of chance of developing geographic atrophy after 7 years. If the drusenoid PED was greater than $2 \mathrm{DD}$ or was associated with metamorphopsia at initial presentation, progression to atrophy or ingrowth of CNV occurred after 2 years $(p<0.01)$.

Indocyanine green angiography confirmed fluorescein angiographic features or ascertained the presence of CNV when fluorescein angiography was equivocal. Optical coherence tomography was helpful in distinguishing coalescent soft drusen from drusenoid PED and disclosed the accumulation of sub or intraretinal fluid in eyes with CNV.

Conclusion: Drusenoid PED size greater than 2 DD and metamorphopsia were risk factors identified at presentation which affected prognosis. The evaluation of the eyes at risk requires the use of all imaging means in order to ascertain the diagnosis of CNV. At long term (over 10 years), geographic atrophy and CNV had occurred in $75 \%$ and $25 \%$ respectively, with a poor visual outcome.
\end{abstract}

$\mathrm{D}$ rusenoid pigment epithelial detachment (PED) is part of the clinical spectrum of age related macular degeneration described by Casswell in $1985 .{ }^{1}$ It is formed by the confluence of large areas of soft drusen and is usually located in the central macula. It may be a marker of a diffuse disturbance at the level of the retinal pigment epithelium (RPE) in relation to age related macular degeneration. ${ }^{2}$ Two hypothetic mechanisms might explain the progressive enlargement. Firstly, the conflence of soft drusen might be associated with an accumulation of membranous debris external to the retinal pigment epithelial basement membrane. Secondly, the lipid nature of this membranous debris creates a hydrophobic barrier in Bruch's membrane, resulting in the accumulation of fluid and enlargement of the detachment. ${ }^{3-6}$
Different types of PED have been identified in the literature. ${ }^{1478}$ Drusenoid PED was clearly distinguished from the other types by its better prognosis. This avascular PED typically develops slowly and causes minimal complaints of blurred vision. The natural history reported in the literature has been progression to persistent drusenoid RPE detachment, geographic atrophy, and neovascularisation. These previous studies suggested that the outcome might be modified with longer follow up. ${ }^{1478}$

An evaluation of the clinical course of untreated drusenoid PED, followed up for a minimum of 1 year, has been performed in a large group of eyes in our department. In order to refine the different clinical outcome, indocyanine green angiography and optical coherence tomography, ${ }^{9-10}$ recently introduced into clinical practice, were performed.

\section{METHODS}

A retrospective review identified 61 eyes of 32 patients who presented with drusenoid PED in our department. Eyes treated with laser photocoagulation were excluded. The diagnostic criteria on stereoscopic colour photograph were a focal area of retinal pigment epithelial detachment involving the macular area, $1 / 2$ disc diameter (DD) in minimal size, often with scalloped borders, slightly irregular surface, with a triradiate pattern of orange or grey pigmentation on its surface surrounded by soft drusen. On fluorescein angiography, the PED appeared with a faint hyperfluorescence in the early phase, then increasing progressively but stabilising in the late phase, without leakage. Borders were often scalloped. Focal hypofluorescence areas corresponded to the masking effect of pigment deposits.

Patients had been routinely examined every 6-12 months. Examination included best corrected visual acuity measurement, biomicroscopic fundus examination, stereoscopic colour photograph, fluorescein angiography (FA), indocyanine green angiography (HRA, Heidelberg, Germany). Optical coherence tomography (Humphey-Zeiss) was performed only at the last examination in selected cases $(30 \%) .{ }^{12}{ }^{13}$

Kaplan Meyer survival analysis was performed to estimate the probability of complication occurence according to the clinical factors (metamorphopsia and PED size larger than 2 DD) at initial presentation.

\section{RESULTS}

The average age of the 32 patients (three men and 29 women) included in the study was 70 years (range 63-82 years). Twenty nine patients $(91 \%)$ presented with drusenoid PED in both eyes. The mean follow up was 4.6 years; 61 eyes were followed for a period of 1 year, 27 eyes (44\%) for a period of 3 years, and 12 eyes (20\%) for a period of $10-17$ years (table 1 ). Thirteen $(40 \%)$ patients were treated for hypercholesterolemia and fifteen $(50 \%)$ for systemic hypertension.

Abbreviations: CNV, choroidal neovascularisation; $\mathrm{DD}$, disc diameter; PED, pigment epithelium detachment; RPE, retinal pigment epithelium. 


\begin{tabular}{|c|c|c|c|c|c|c|c|c|c|c|}
\hline Patien & $t$ Eye & Age & Sex & $\begin{array}{l}\text { Metamor- } \\
\text { phopsia }\end{array}$ & $\begin{array}{l}\text { - Follow up } \\
\text { (months) }\end{array}$ & $\begin{array}{l}\text { Initial } \\
\text { VA }\end{array}$ & $\begin{array}{l}\text { Initial size } \\
\text { (DD) }\end{array}$ & $\begin{array}{l}\text { e Final } \\
\text { VA }\end{array}$ & $\begin{array}{l}\text { Final size } \\
\text { (DD) }\end{array}$ & Outcome \\
\hline \multirow[t]{2}{*}{1} & Right & 72 & $\mathrm{~F}$ & + & 42 & $20 / 40$ & 1.0 & $20 / 800$ & 1.0 & Atrophy \\
\hline & Left & 72 & $\mathrm{~F}$ & - & 42 & $20 / 40$ & 1.0 & $20 / 40$ & 1.0 & Atrophy \\
\hline \multirow[t]{2}{*}{2} & Right & 70 & $\mathrm{~F}$ & - & 84 & $20 / 32$ & 0.5 & $20 / 400$ & 2.0 & CNV \\
\hline & Left & 70 & $\mathrm{~F}$ & - & 84 & $20 / 26$ & 0.5 & $20 / 50$ & 1.0 & Persistence \\
\hline 3 & Right & 66 & M & - & 36 & $20 / 50$ & 0.5 & $20 / 60$ & 0.5 & Atrophy \\
\hline \multirow[t]{2}{*}{4} & Right & 72 & $\mathrm{~F}$ & - & 120 & $20 / 26$ & 1.0 & $20 / 60$ & 1.5 & Atrophy \\
\hline & Left & 72 & $\mathrm{~F}$ & + & 120 & $20 / 40$ & 1.0 & $20 / 400$ & 1.5 & Atrophy \\
\hline \multirow[t]{2}{*}{5} & Right & 77 & $\mathrm{~F}$ & + & 24 & $20 / 60$ & 1.0 & $20 / 100$ & 1.0 & Atrophy \\
\hline & Left & 77 & $\mathrm{~F}$ & - & 24 & $20 / 32$ & 0.5 & $20 / 40$ & 1.0 & Persistence \\
\hline \multirow[t]{2}{*}{6} & Right & 75 & $\mathrm{~F}$ & - & 24 & $20 / 400$ & 1.0 & $20 / 800$ & 0.5 & Atrophy \\
\hline & Left & 75 & $\mathrm{~F}$ & - & 24 & $20 / 100$ & 0.5 & $20 / 400$ & 0.5 & Atrophy \\
\hline \multirow[t]{2}{*}{7} & Right & 77 & $\mathrm{~F}$ & - & 24 & $20 / 126$ & 1.5 & $20 / 400$ & 1.5 & Persistence \\
\hline & Left & 77 & $\mathrm{~F}$ & - & 24 & $20 / 40$ & 1.5 & $20 / 400$ & 1.5 & Persistence \\
\hline \multirow[t]{2}{*}{8} & Right & 66 & $\mathrm{~F}$ & + & 24 & $20 / 60$ & 1.0 & $20 / 60$ & 1.5 & Persistence \\
\hline & Left & 66 & $\mathrm{~F}$ & - & 24 & $20 / 50$ & 1.0 & $20 / 50$ & 1.0 & Persistence \\
\hline \multirow[t]{2}{*}{9} & Right & 72 & $\mathrm{~F}$ & - & 24 & $20 / 50$ & 0.5 & $20 / 100$ & 1.0 & Persistence \\
\hline & Left & 72 & $\mathrm{~F}$ & - & 24 & $20 / 80$ & 0.5 & $20 / 200$ & 1.0 & Persistence \\
\hline \multirow[t]{2}{*}{10} & Right & 64 & $\mathrm{~F}$ & - & 204 & $20 / 26$ & 0.5 & $20 / 200$ & 3.0 & CNV \\
\hline & Left & 64 & $\mathrm{~F}$ & - & 204 & $20 / 26$ & 1.0 & $20 / 200$ & 2.0 & Atrophy \\
\hline 11 & Left & 66 & $\mathrm{~F}$ & - & 24 & $20 / 40$ & 1.0 & $20 / 40$ & 1.0 & Persistence \\
\hline \multirow[t]{2}{*}{12} & Right & 70 & $\mathrm{~F}$ & + & 36 & $20 / 100$ & 2.0 & $20 / 100$ & 3.0 & Atrophy \\
\hline & Left & 70 & $\mathrm{~F}$ & - & 36 & $20 / 32$ & 2.0 & $20 / 60$ & 2.0 & Atrophy \\
\hline 13 & Right & 69 & $\mathrm{~F}$ & + & 24 & $20 / 40$ & 1.5 & $20 / 400$ & 1.5 & CNV \\
\hline \multirow[t]{2}{*}{14} & Right & 75 & $\mathrm{~F}$ & - & 30 & $20 / 40$ & 0.5 & $20 / 60$ & 0.5 & Persistence \\
\hline & Left & 75 & $\mathrm{~F}$ & - & 30 & $20 / 40$ & 1.0 & $20 / 60$ & 10 & Persistence \\
\hline \multirow[t]{2}{*}{15} & Right & 75 & M & - & 84 & $20 / 26$ & 1.0 & $20 / 40$ & 1.5 & Persistence \\
\hline & Left & 75 & M & - & 84 & $20 / 40$ & 1.0 & $20 / 50$ & 1.5 & Persistence \\
\hline \multirow[t]{2}{*}{16} & Right & 70 & $\mathrm{~F}$ & - & 72 & $20 / 50$ & 3.0 & $20 / 400$ & 4.0 & CNV \\
\hline & Leff & 70 & $\mathrm{~F}$ & - & 72 & $20 / 50$ & 3.0 & $20 / 800$ & 5.0 & CNV \\
\hline 17 & Right & 66 & $\mathrm{~F}$ & - & 120 & $20 / 126$ & 2.0 & $20 / 126$ & 3.0 & Atrophy \\
\hline & Left & 66 & $\mathrm{~F}$ & - & 120 & $20 / 26$ & 2.0 & $20 / 200$ & 3.0 & CNV \\
\hline 18 & Right & 63 & $\mathrm{~F}$ & + & 156 & $20 / 100$ & 1.0 & $20 / 50$ & 1.5 & Atrophy \\
\hline & Left & 63 & $\mathrm{~F}$ & + & 156 & $20 / 40$ & 1.5 & $20 / 800$ & 5.0 & CNV \\
\hline 19 & Right & 70 & $\mathrm{~F}$ & + & 180 & $20 / 32$ & 1.0 & $20 / 400$ & 4.0 & Atrophy \\
\hline & Left & 70 & $\mathrm{~F}$ & - & 180 & $20 / 126$ & 1.0 & $20 / 800$ & 4.0 & Atrophy \\
\hline 20 & Right & 70 & M & + & 120 & $20 / 40$ & 1.0 & $20 / 200$ & 1.0 & Atrophy \\
\hline & Left & 70 & M & + & 120 & $20 / 32$ & 1.0 & $20 / 50$ & 1.0 & Atrophy \\
\hline 21 & Right & 63 & $\mathrm{~F}$ & - & 60 & $20 / 40$ & 0.5 & $20 / 40$ & 0.5 & Persistence \\
\hline & Left & 63 & $\mathrm{~F}$ & - & 60 & $20 / 40$ & 0.5 & $20 / 60$ & 0.5 & Atrophy \\
\hline 22 & Right & 67 & $\mathrm{~F}$ & - & 24 & $20 / 126$ & 1.5 & $20 / 800$ & 1.5 & Atrophy \\
\hline & Left & 67 & $\mathrm{~F}$ & - & 24 & $20 / 60$ & 1.5 & $20 / 40$ & 1.5 & Persistence \\
\hline 23 & Right & 72 & $\mathrm{~F}$ & + & 18 & $20 / 100$ & 4.0 & $20 / 400$ & 4.0 & Atrophy \\
\hline & Left & 72 & $\mathrm{~F}$ & - & 18 & $20 / 32$ & 4.0 & $20 / 32$ & 4.0 & Persistence \\
\hline 24 & Right & 72 & $\mathrm{~F}$ & - & 60 & $20 / 26$ & 1.0 & $20 / 200$ & 1.0 & Atrophy \\
\hline & Left & 72 & $\mathrm{~F}$ & _- & 60 & $20 / 60$ & 2.0 & $20 / 400$ & 2.0 & Atrophy \\
\hline 25 & Right & 62 & $\mathrm{~F}$ & + & 18 & $20 / 200$ & 3.0 & $20 / 400$ & 4.0 & $\mathrm{CNV}$ \\
\hline & Left & 62 & $\mathrm{~F}$ & + & 18 & $20 / 400$ & 3.0 & $20 / 400$ & 3.0 & Atrophy \\
\hline 26 & Right & 66 & $\mathrm{~F}$ & - & 24 & $20 / 50$ & 1.0 & $20 / 60$ & 1.0 & Persistence \\
\hline & Left & 66 & $\mathrm{~F}$ & + & 24 & $20 / 200$ & 1.0 & $20 / 200$ & 1.0 & Atrophy \\
\hline 27 & Right & 82 & $\mathrm{~F}$ & + & 12 & $20 / 50$ & 1.0 & $20 / 50$ & 1.0 & Persistence \\
\hline & Left & 82 & $\mathrm{~F}$ & - & 12 & $20 / 26$ & 0.5 & $20 / 32$ & 1.0 & Persistence \\
\hline 28 & Right & 71 & $\mathrm{~F}$ & + & 24 & $20 / 100$ & 1.0 & $20 / 60$ & 1.0 & Atrophy \\
\hline & Left & 71 & $\mathrm{~F}$ & + & 24 & $20 / 60$ & 1.0 & $20 / 60$ & 0.5 & Atrophy \\
\hline 29 & Right & 68 & $\mathrm{~F}$ & - & 24 & $20 / 40$ & 1.0 & $20 / 100$ & 1.0 & Atrophy \\
\hline & Left & 68 & $\mathrm{~F}$ & - & 24 & $20 / 20$ & 0.5 & $20 / 20$ & 1.0 & Persistence \\
\hline 30 & Right & 65 & $\mathrm{~F}$ & + & 12 & $20 / 40$ & 2.0 & $20 / 200$ & 3.0 & Atrophy \\
\hline & Left & 65 & $\mathrm{~F}$ & + & 12 & $20 / 40$ & 2.0 & $20 / 100$ & 2.0 & Atrophy \\
\hline 31 & Right & 67 & $\mathrm{~F}$ & - & 18 & $20 / 26$ & 0.5 & $20 / 50$ & 0.5 & Persistence \\
\hline & Left & 67 & $\mathrm{~F}$ & + & 18 & $20 / 50$ & 1.0 & $20 / 100$ & 1.0 & Persistence \\
\hline 32 & Right & 75 & $\mathrm{~F}$ & + & 18 & $20 / 60$ & 1.0 & $20 / 60$ & 1.5 & Persistence \\
\hline & Left & 75 & $\mathrm{~F}$ & + & 18 & $20 / 60$ & 1.5 & $20 / 60$ & 1.0 & Atrophy \\
\hline
\end{tabular}

At first examination, patients complained of metamorphopsia in $40 \%$ of cases. Visual acuity was $20 / 40$ or better in 33 eyes (54\%), 20/50 to $20 / 100$ in 24 eyes ( $40 \%$ ), and $20 / 200$ or worse in four eyes $(6 \%)$.

Three different clinical patterns were observed during the follow up period: drusenoid PED persisted in 23 eyes of 61 (38\%), atrophy developed in 30 eyes $(49 \%)$, and choroidal neovascularisation (CNV) developed in eight eyes (13\%). Of the 12 eyes with a follow up of 10 years or more, three eyes (25\%) developed CNV and subsequently progressed to fibrovascular scars, and nine eyes (75\%) developed macular geographic atrophy (fig 1).
In 23 eyes (38\%), the drusenoid PED increased in size or remained unchanged (fig 3 ). Final visual acuity was $20 / 40$ or better in eight eyes (35\%), 20/50 to $20 / 100$ in 12 eyes (52\%), and $20 / 200$ or worse in three eyes (13\%) (fig 2). Eyes with poor visual acuity $(\mathrm{VA}<20 / 100)$ at baseline presented with focal foveal atrophy within the drusenoid PED responsible for this poor vision. Eyes were included in atrophy group when the atrophic area replaced the initial drusenoid RPE detachment. Thus, when atrophy concerned limited areas within the drusenoid PED, the eyes were included in the persistent form group.

In 30 eyes (49\%), the drusenoid PED was replaced by an atrophic area (fig 4). Final visual acuity was 20/40 in one eye 


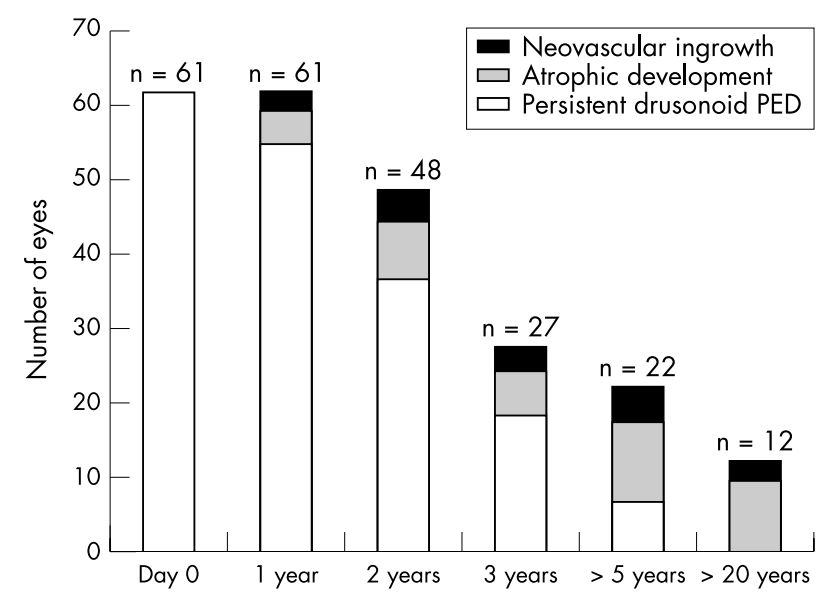

Figure 1 Evolution of drusenoid RPE detachement in relation to follow up.

(4\%), $20 / 50$ to $20 / 100$ in 13 eyes (43\%), and $20 / 200$ or worse in 16 eyes $(53 \%)$. In the five eyes with a follow up of more than 15 years, final visual acuity was worse than 20/100 (fig 2).

Eight eyes (13\%) developed CNV (fig 5). At final examination, four additional eyes developed a disciform lesion. The eight eyes (100\%) had a visual acuity of $20 / 200$ or less (fig 2).

Based on Kaplan Meyer survival analysis, patients with drusenoid PED had a 50\% of chance of developing geographic atrophy after seven years. If the drusenoid PED was larger than 2 DD or was associated with metamorphopsia at initial presentation, progression to atrophy occurred after two years $(\mathrm{p}=0.0016$ for metamorphopsia and $\mathrm{p}=0.01$ for initial size larger than 2 DD). Similarly, if the two clinical factors were present initially (metamorphopsia or drusenoid PED superior

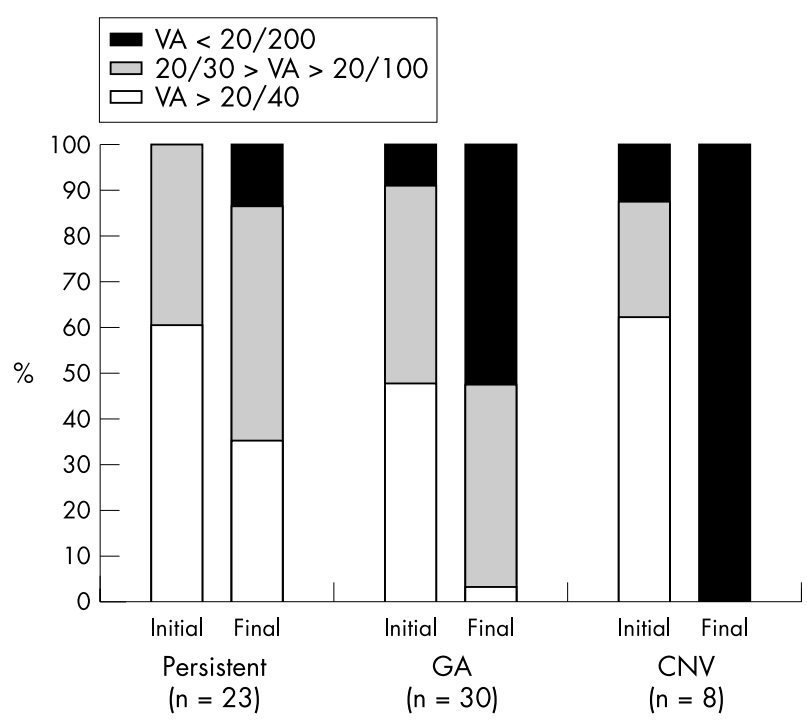

Figure 2 Initial and final visual acuity according to the anatomic type of outcome

to $2 \mathrm{DD})$, the time elapse of $\mathrm{CNV}$ occurrence was reduced to two years $(p=0.0002$ for metamorphopsia and $p=0.0006$ for initial size larger than 2 DD).

\section{DISCUSSION}

Different means of examination have allowed documentation of the course of drusenoid material over a period of 4.6 years (range 1-17 years). Fluorescein angiography analysis was challenging. Three different patterns of hyperfluorescence may develop: the typical delayed and regular hyperfluorescence, without leakage, sprinkled with hypofluorescent foci corresponding to pigment deposits, the areas of intense

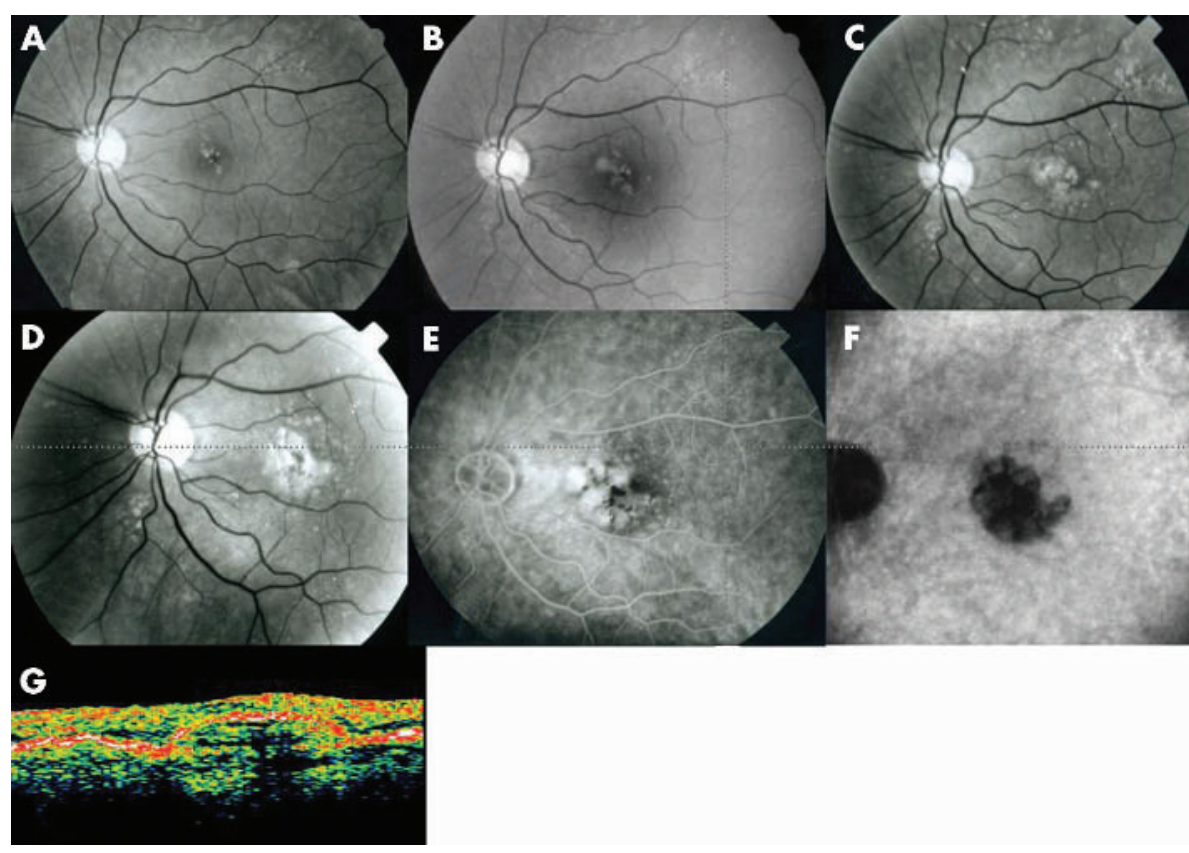

Figure 3 Progression of soft drusen to drusenoid retinal pigment epithelial detachment over a 15 year period. (A) Red free photograph, at presentation: small number of hard drusen and soft drusen in the central macular area. (B) Red free photograph, 5 years later: increase of hard drusen, soft drusen, and confluent soft drusen. (C) Red free photograph, 9 years later: occurrence of a drusenoid RPE detachment secondary to coalescence of confluent soft drusen. (D) Red free photograph, 15 years later: the drusenoid RPE detachment has increased in size and pigment mottling appeared. (E) On the ate phase of the corresponding fluorescein angiography, the detachment is hyperfluorescent with masking at the site of pigment mottling. (F) On late phase of the corresponding indocyanine green angiography, the drusenoid RPE detachment masks the underlying choroidal vasculature. The hypofluorescence is increased at the site of pigment mottling. There is no sign of choroidal neovascularisation. (G) On optical coherence tomography, the drusenoid RPE detachment is characterised by a moderately reflective area underneath the smooth progressive elevation of the hyperreflective band of the pigment epithelium 


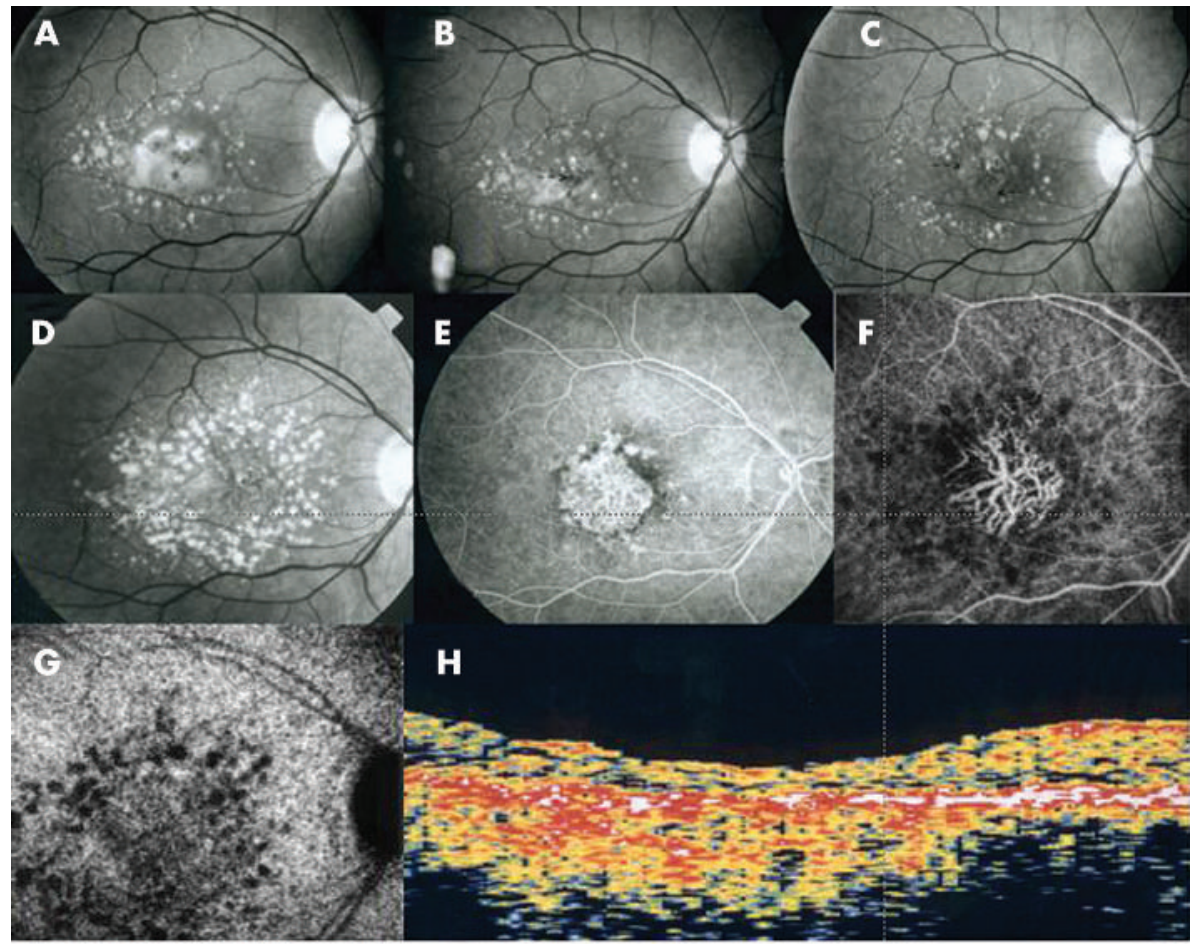

Figure 4 Progression of a drusenoid retinal pigment epithelial detachment to geographic atrophy over a 13 year period. (A) Red free photograph, at presentation: the central drusenoid RPE detachment with pigment mottling is surrounded by some soft and regressing drusen around. (B) Red free photograph, 2 years later: a small atrophic zone (arrows) appeared within the RPE detachment. (C) Red free photograph, 5 years later: a central, well limited white atrophic area (arrows) developed. (D) Red free photograph, 13 years later: progression to geographic atrophy. $(E)$ The late phase of the corresponding fluorescein angiogram shows staining of the atrophic area. (F) On indocyanine angiography, in the early phase, hyperfluorescence of the large underlying choroidal vessels in the area of geographic atrophy. $(G)$ In the late phase, the hyperfluorescence of the atrophic area is similar to that of the background. Surrounding soft drusen appear hypofluorescent. (H) Optical coherence tomography shows a well defined region of increased reflectivity at the level of the RPE band. The contour of the foveal depression is altered, and the normal minimally reflective band corresponding to the retinal photoreceptor layer is absent. The retinal thickness is decreased in the foveal region.

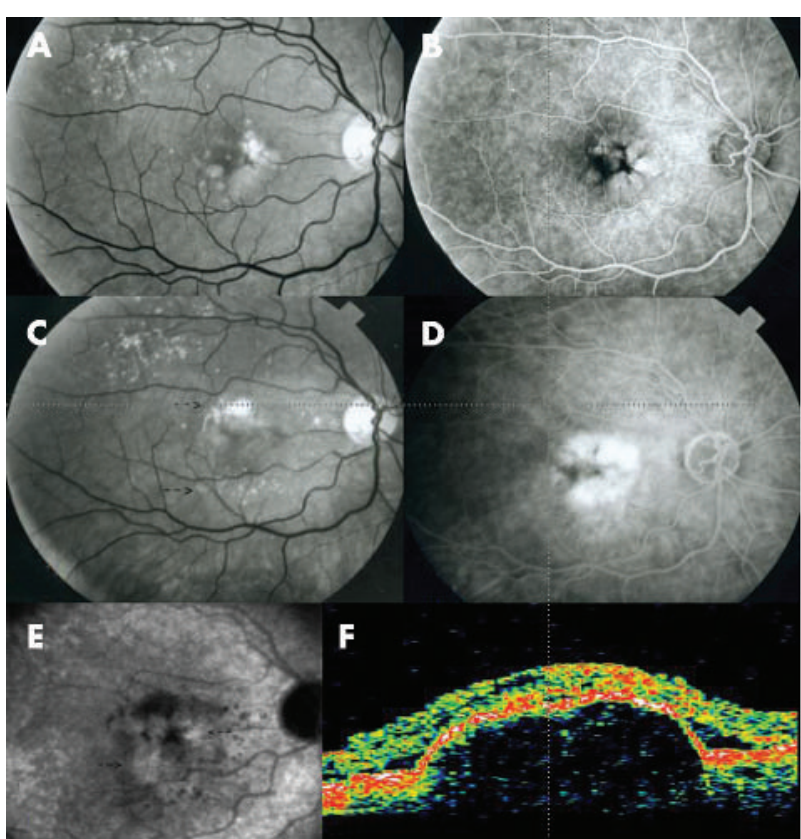

Figure 5 Progression of a drusenoid RPE detachment to choroidal neovascularisation (CNV) over a 6 year period. (A) Red free photograph, at presentation: drusenoid RPE detachment. (B) The late phase of the corresponding fluorescein angiography shows a hyperfluorescence with masking caused by pigment mottling. There is no late dye leakage. (C) Red free photograph, 6 years later, serous retinal detachment in the macular area (arrows). (D) The late phase of the corresponding fluorescein angiography shows intense

hyperfluorescence of the detachment. (E) The late phase of indocyanine green angiography shows a hyperfluorescent zone in the macular area suggesting of CNV (arrows). (F) Optical coherence tomography shows sub and intraretinal fluid as an hyporeflectivity and a lower reflectivity of the detachment. This aspect corresponds with the presence of CNV. hyperfluorescence with sharp borders of atrophy either focal or central, replacing the drusenoid PED, or finally, the uneven hyperfluorescence associated with late intense staining of the RPE detachment and leakage of choroidal neovascularisation. Indocyanine green angiography was very helpful in differentiating the three different forms of hyperfluorescence and in locating the presence and the exact site of CNV in order to consider laser treatment. ${ }^{9-11}$

Optical coherence tomography was performed in selected patients $(30 \%)$ to analyse different features of drusenoid PED. The progression from the typical hyperreflectivity of the drusenoid material surrounded by coalescent soft drusen progressively to less hyperreflectivity, possibly because of fluid retention. The presence of subretinal or intraretinal fluid and the increase in material hyporeflectivity was associated with CNV. Direct identification and location of CNV was hidden by the hyperreflective band of the retinal pigment epithelium-Bruch's membrane-choriocapillaris layers. ${ }^{12}{ }^{13}$

In the present study, $67 \%$ of 61 eyes remained stable, whereas 33\% progressed to geographic atrophy or CNV at three years. In Casswell's and Hartnett's studies, $60 \%$ of 15 eyes and $22 \%$ of 23 eyes remained unchanged for an average period of two years ${ }^{1}$ and 3.4 years $^{7}$ respectively. Geographic atrophy was the most common end stage in $49 \%$ of the 61 eyes. This proportion increased with longer follow up (nine eyes $(75 \%)$ after 10 years or more). Visual acuity decreased to less than $20 / 100$ in $40 \%$ of eyes in Casswell's study after two years, ${ }^{1}$ in $65 \%$ in Hartnett's study after 3.4 years $^{7}$ and in $58 \%$ in our study after 4.6 years. Visual outcome was worse in our study than in the previous studies, possibly due to longer follow up.

Eyes with poor visual acuity $(\mathrm{VA}<20 / 100)$ at baseline have developed geographic atrophy at long term in $85 \%$. Focal foveal atrophy within the drusenoid PED responsible for this decrease of visual acuity is the initial stage of PED's regression. In our study, eyes were only included in the 
atrophic group when it replaced the initial drusenoid RPE detachment. Limited areas of atrophy within the drusenoid PED were included in the persistent group. The poor vision at both baseline and follow up in the persistence group was because of subfoveal focal atrophy with partial persistence of drusenoid material. ${ }^{14} 15$

In our study, CNV was relatively frequent (13\% of eyes during the whole follow up, $11 \%$ at three years, $23 \%$ after five years, and $25 \%$ of eyes after a 10 year period) whereas in Hartnett's study it was of $9 \%$ of eyes after 3.4 years ${ }^{7}$ and none in Casswell's study. This limited number of patients and this short follow up might account for these results. In addition, indocyanine green angiography not available at the time together with the specificity of referral centre of our department might be responsible for the increased incidence of CNV.

Formation and persistence of the drusenoid PED, in elderly patients harbouring soft drusen, probably corresponds with the evolution of a distinct subgroup of age related macular degeneration. Results of survival analyses have allowed us to estimate the outcome of drusenoid PED according to the presentation features. The natural history of a drusenoid PED inferior to $2 \mathrm{DD}$ or without metamorphopsia will result in atrophy after seven years follow up. Conversely, if the herein identified factors are present, time elapse to CNV proliferation is shortened with $50 \%$ risk at two years.

Drusenoid PED with large and confluent soft drusen is included in the 3 a subgroup of the randomised, placebocontrolled, clinical trial of high dose supplementation with antioxidants and vitamins A, C, and E (AREDS). This supplementation might decrease the progression to atrophy and $\mathrm{CNV}$, although the trial did not report specifically on drusenoid PED. ${ }^{16}$

In conclusion, patients with drusenoid PED can be informed of their possible outcome, according to the clinical risk factors at presentation. Antioxidants and vitamin supplementation could be considered.

\section{Authors' affiliations \\ W Roquet, G Coscas, G Soubrane, Clinique Ophtalmologique Universitaire de Créteil, France F Roudot-Thoraval, Service Santé Publique Hopital Henri-Mondor Créteil, France}

Correspondence to: $\operatorname{Dr} \mathrm{G}$ Soubrane, Clinique Ophtalmologique Universitaire de Créteil, 40 avenue de Verdun, 94200 Créteil, France; gisele.soubrane@chicreteil.fr

Accepted 15 September 2003

\section{REFERENCES}

1 Casswell AG, Kohen D, Bird AC. Retinal pigment epithelial detachments in the elderly: classification and outcome. Br J Ophthalmol 1985;69:397-403.

2 Gass JDM. Stereoscopic atlas of macular diseases: diagnosis and management, 3rd edition. Mosby, ed. St Lovis, MO 1987:82-3 and 1034-5.

3 Abdelsalam A, Del Priore L, Zarbin MA. Drusen in age-related macular degeneration: pathogenesis, natural course, and laser photocoagulationinduced regression. Surv Ophthalmol 1999;44:1-29.

4 Bird AC, Marshall J. Retinal pigment epithelial detachments in the elderly. Trans Ophthalmol Soc U K 1986;105:674-82.

5 Sarks JP, Sarks SH, Killingsworth MC. Evolution of soft drusen in age-related macular degeneration. Eye 1994:8:269-83.

6 Bressler NM, Silva JC, Bressler SB, et al. Clinicopathologic correlation of drusen and retinal pigment epithelial abnormalities in age-related macular degeneration. Retina 1994;14:130-42.

7 Hartnett ME, Weiter JJ, Garsd A, et al. Classification of retinal pigment epithelial detachments associated with drusen. Graefes Arch Clin Exp Ophthalmol 1992;230:11-19.

8 Coscas G, Glaser B, Green W, et al. Dégénérescences maculaires acquises liées à l'age et néovaisseaux sous-rétiniens. In: Masson, ed. Paris, 1991:191-208 and 259-304.

9 Regillo CD. The present role of indocyanine green angiography in ophthalmology. Curr Opin Ophthalmol 1999;10:189-96.

10 Quaranta M, Buglione M, Lo Schiavo Elia R, et al. Angiographie au vert $\mathrm{d}^{\prime}$ indocyanine des drusen de la membrane basale de l'épithélium pigmentaire rétinien associés à du matériel pseudo-vitelliforme. J Fr Ophtalmol 1998;21:185-90.

11 Arnold JJ, Quaranta M, Soubrane G, et al. Indocyanine green angiography of drusen. Am J Ophthalmol 1997;124:344-56

12 Hee MR, Baumal CR, Puliafito CA, et al. Optical coherence tomography of age-related macular degeneration and choroidal neovascularization. Ophthalmology 1996;103:1260-70.

13 Puliafito CA, Hee MR, Lin CP, et al. Imaging of macular diseases with optical coherence tomography. Ophthalmology 1995;102:217-29.

14 Sunness JS, Gonzalez-Baron J, Applegate CA, et al. Enlargement of atrophy and visual acuity loss in the geographic atrophy form of age-related macular degeneration. Ophthalmology 1999;106:1768-79.

15 Sunness JS, Gonzalez-Baron J, Bressler NM, et al. The development of choroidal neovascularization in eyes with the geographic atrophy form of age-related macular degeneration. Ophthalmology 1999;106:910-19

16 Age-Related Eye Disease Study Research Group. A randomized, placebocontrolled, clinical trial of high-dose supplementation with vitamins $\mathrm{C}$ and $\mathrm{E}$, Beta Caroten, and Zinc for age-related macular generetion and vision loss. Arch opthalmol 2001;119:1417-36. 